Psychology of Language and Communication 2018, Vol. 22, No. 1

\title{
Sciendo
}

DOI: $10.2478 /$ plc-2018-0014

\author{
IZABELA KACZMAREK ${ }^{1}$, SŁAWOMIR JABŁOŃSKI², PAWEŁ KLEKA², \\ BARBARA STEINBORN ${ }^{1}$ \\ ${ }^{1}$ Poznan University of Medical Science, Poznan, Poland \\ ${ }^{2}$ Adam Mickiewicz University, Poznan, Poland
}

\section{EFFICIENCY OF EXECUTIVE FUNCTIONS AND LITERACY AMONG CHILDREN WITH SPECIFIC LANGUAGE IMPAIRMENT}

\begin{abstract}
Recently, extensive studies investigating executive functions in children with specific language impairment (SLI) have been performed. In the present study, we compared the level of executive functions (i.e., inhibitory control and cognitive flexibility) and literacy skills between 53 healthy children and 53 children with SLIs between the ages of 3 and 11 years. The groups were matched by age, gender and parental education level. Executive functions were assessed using the Children Card Sort, and the Literacy Assessment Battery was applied to measure literacy skills. The patients with SLI displayed a significantly lower level of cognitive flexibility than that of the healthy children. No significant differences were observed between the groups in inhibitory control and the majority of literacy skills. The results confirm the hypothesis that patients with SLI experience difficulties in cognitive flexibility.
\end{abstract}

Key words: executive functions, inhibitory control, cognitive flexibility, specific language impairment, literacy, sorting task, children

\section{Introduction}

Abnormalities in speech and language development are sensitive indicators of developmental problems and, frequently, symptoms of wider and more severe developmental disorders (O'Hare \& Bremner, 2016). The incidence of delays in the development of speech is estimated to be $3.8 \%$ in 6-year-old children (Shriberg, Tomblin, \& McSweeny, 1999) and .5\%-19\% in younger children (McLaughlin, 2011), depending on the adopted diagnostic criteria.

Address for correspondence: Izabela Kaczmarek, Laboratory of Developmental Neuropsychology, Department and Clinic of Developmental Neurology, Poznan University of Medical Science, Przybyszewskiego 49, 60-355 Poznań, Poland. E-mail: ikaczmarek@ump.edu.pl 
Among the abnormalities in the development of speech and language, particular attention should be paid to a group of disorders called specific language impairment (SLI) (Conti-Ramsden et al., 2014). A characteristic trait associated with SLI is the atypical acquisition of skills associated with speech and language in children with typical nonverbal development.

Disorders in the development of speech and language are known to co-occur with deficits in executive functions (EFs) (Weismer, 2013) and reading difficulties (Horowitz-Kraus, Finucane, 2016). Therefore, it is important to further investigate the relationships between diagnosed language disorders and deficits in EFs as well as literacy skills. As regards executive functions, many studies indicate that "language is the key to EF performance rather than vice versa" (Botting et al., p. 1, 2017, Lindstone, Meins, \& Fernyhough, 2012). Additionally, the development of speech and executive functions appear to be crucial for literacy achievement during the school years (HorowitzKraus, Finucane, 2016). The present study compared executive functions and literacy skills of monolingual children diagnosed with SLI and their typically developing peers.

\section{Specific language impairment (SLI)}

Tomblin and colleagues conducted extensive and commonly cited studies indicating that approximately 7\% of English-speaking kindergarten children manifest symptoms of a specific language impairment (Tomblin et al., 1997). This finding suggests that this disorder has a high prevalence that is comparable to the incidence of attention deficit hyperactivity disorder (ContiRamsden et al., 2014). The typical symptoms manifested by children with SLI initially resemble a delay in the development of speech; however, over time, the children exhibit a constellation of problems that can affect the following diverse aspects of language competencies: phonological, lexical, morphological, syntactic or pragmatic-semantic (Leonard, 2014). Notably, a diagnosis of SLI is a significant risk factor for the occurrence of reading and writing difficulties in school-aged children (Isoaho, Kauppila, Launonen, 2015, Williams, Larkin, Blaggan, 2013). Other impairments associated with this risk factor include problems with interpersonal relationships and irregularities in emotions and behaviour, particularly in patients with severe and difficult-to-treat forms of the disorder (Conti-Ramsden et al., 2013; Redmond \& Rice, 1998).

Although the aetiology of the abovementioned difficulties remains unclear, researchers have identified the following factors as possible causes of these problems: genetic (Li \& Bartlett, 2012, Rice, 2013), neurobiological (Mayes, Reilly, \& Morgan, 2015), environmental (Cuevas et al., 2014), linguistic (Bishop, 2006) and cognitive deficits (Kapa \& Plante, 2015). Recently, the number of studies on cognitive deficits in SLI has significantly increased. Two lines of research have been followed to investigate cognitive difficulties in 
SLI: assessments of verbal development and evaluations of nonverbal processes (see Kapa \& Plante, 2015). Verbal deficits include deficits in working memory (Montgomery, Magimairaj, \& Finney, 2010), limited phonological loop and episodic buffer (Petrucelli, Bavin \& Bretherton, 2012), and problems in auditory processing (Cumming, Wilson, \& Goswami 2015). Non-verbal deficits include a delay in the speed of responses (Miller, Kail, \& Leonard et al., 2001) and problems in motor control and coordination (Flapper \& Schoemaker, 2013). A comprehensive discussion of this topic can be found in the work of Kapa and Plante (2015). An important line of research investigating the cognitive deficits in SLI focuses on executive functions, which are discussed in the following section of this paper.

\section{Executive functions}

Executive functions are defined as higher mental processes that enable planning, executing and controlling actions in problem-solving (Miyake et al., 2000, Diamond, 2013). The term EFs has been proposed as an "umbrella term" that combines several mental components engaged in a purposeful behaviour (Chan et al., 2008). The well-established conceptualisation of EFs proposed by Miyake contains the following three main components: inhibitory control, cognitive flexibility and working memory (Miyake et al., 2000). According to this theory, inhibitory control (also called the suppression process) is the ability to stop an automatic response and resist distractor interference, whereas cognitive flexibility is the capacity to adapt cognitive sets to changing environmental demands (Miyake et al., 2000). Working memory is a cognitive construct that refers to the process of the short-term storage and management of information (Miyake et al., 2000). Diamond (2013) proposed a theory of the dynamics of EF development suggesting that inhibitory control, which constitutes the basis of the other components of EFs, plays a crucial role in the formation of executive processes. Studies exploring both inhibition and flexibility have shown that the most intensive development of inhibitory control occurs between the ages of 3 and 5 and cognitive flexibility develops most intensively between the ages of 7 and 8 (Diamond, 2013; Zelazo et al., 2003; see also: Jabłoński et al., 2013). Importantly, Barkley (1997) suggests that working memory relies on an intact suppression processes. Moreover, due to the superordinate role of inhibitory control and cognitive flexibility in the formation of higher-level executive functions (such as problem-solving, reasoning and planning), investigating the two processes appears particularly important. Additionally, as shown by previous studies, inhibitory control and cognitive flexibility have a direct impact on academic skills. The level of development of executive processes strongly correlates with school readiness (Molfese et al., 2010, Jacobson, Williford, \& Pianta, 2011), counting skills (Clark et al., 2013) and literacy (Blair \& Razza 2007, Horowitz-Kraus, Finucane, 2016). 


\section{SLI, executive functions and literacy}

Annually, the number of studies confirming the existence of a relationship between language skills and executive functions - including inhibitory control and cognitive flexibility - in children with SLI increases steadily (Bishop \& Norbury, 2005, Farrant et al., 2012, Henry, Messer, \& Nash, 2012, Pauls $\&$ Archibald, 2016). Studies employing verbal measures of executive functions (including reading and listening tasks, processing and storage skills in the verbal domain) have found that children diagnosed with SLI performed worse on those measures than their typically developing counterparts (Lukács et al. 2016, Leonard et al., 2013). The cognitive limitations in the SLI group are not limited to verbal skills, but findings from studies exploring this domain are rather inconsistent (Kapa \& Plante, 2015, Vissers et al., 2015). Several studies support the hypothesis that children with SLI have a lowered level of nonverbal inhibition (Marton et al., 2012, Farrant, Maybery, \& Fletcher, 2012, Im-Bolter, Johnson, \& Pascual-Leone, 2006, Henry, Messer, \& Nash, 2012, Spaulding, 2010). However, other studies did not find support for this hypothesis (Lukács et al. 2016). Marton (2008) performed a study using the sorting task paradigm and showed that children with SLI exhibit more preservative errors than their typically developing (TD) peers. The author concluded that tasks that require an increased amount of attentional control and a greater involvement of executive functions are more difficult for children with SLI than for children who develop typically. Similar results were obtained by Bishop and Norbury (2005), who showed that children with SLI perform worse than TD peers on nonverbal inhibition tasks. A meta-analysis conducted by Pauls and Archibald (2016) investigating studies involving 4- to 14-year-old children with SLI and normally developing children also suggested that this population of patients exhibits difficulties in cognitive flexibility and inhibitory control. The possible links between SLI and EFs provide a rationale for using measures of EFs to screen young children at risk of SLI. The available EF assessment tools can be applied to children as young as 2.5 years of age (e.g., A-not-B Task, Delayed Alternation Task) (Epsy et al., 2001).

As previously stated, both a low level of EFs and SLI could be risk factors for school achievements (Blair \& Razza 2007, Molfese et al., 2010, Jacobson, Williford \& Pianta, 2011, Clark et al., 2013, Horowitz-Kraus, Finucane, 2016). Many studies indicate important links between executive functions, level of language development, and reading and writing acquisition (Molfese et al., 2010, Jacobson, Williford, \& Pianta, 2011, Blair \& Razza 2007, Horowitz-Kraus, Finucane, 2016). The development of literacy not only predicts school success but also predicts a high quality of life in adulthood (Beswick \& Sloat, 2006; Kwieciński, 2002). Therefore, monitoring the development of reading and writing abilities in children with SLI has become particularly significant. Crucially, the development of literacy 
begins long before children are formally taught to read and write and occurs simultaneously with the rapidly progressing speech and EF development from approximately the age of three years (Altemeier, Abbott, \& Berninger, 2008; Doebel, Zelazo, 2016; Jabłoński, 2002, 2015). Therefore, in the present study children between the ages of 3 and 11 were investigated. The selected age range includes both the period of intensive development of executive functions and speech and the initial period of academic skills development, allowing for an investigation of the mutual relationships among these competencies.

The primary aim of the current study was to compare executive functions and literacy between typically developing children and children suffering from SLI. Based on recent studies in the field, we predict that an impairment in speech development coexists with a delayed development of executive functions and a delayed development of reading and writing skills. Consequently, we formulated the following two hypotheses: 1) typically developing children outperform SLI children in EFs, and 2) typically developing children outperform SLI children in literacy measures. In addition, our study aimed to determine the feasibility of using the following two new methods of testing: the Children Card Sort (CCS) to assess EFs and the Literacy Assessment Battery (LAB) to measure literacy skills. The aim of this study was to determine whether these tools could be used to screen children for SLI.

\section{Material and methods}

\section{Participants}

The current study is part of a larger research project (see the authors' note) involving 1103 healthy children and 53 children with SLI, aged from 3 to 11. All examinations of the children in both groups were conducted during approximately 40 -minute-long sessions by specially trained researchers.

The healthy children were recruited from the kindergartens and schools they attended. All patients from the impaired group met the SLI criteria based on the ICD-10 classification (WHO, 1992). A licensed speech-language pathologist made the diagnoses based on the patients' history of language development and a clinical assessment (e.g., Tarkowski's Test, Sprawności Językowej, 1992). A full spectrum of differential diagnoses were made for the patients at the Department of Developmental Neurology. At the time of the assessment, all children exhibited problems with expressive language, but no child displayed difficulties in receptive language. Information regarding the type, duration and effectiveness of speech therapy in the group of children with SLI is lacking. The SLI inclusion/exclusion criteria are listed in Table 1. 
Table 1. Inclusion and exclusion criteria for the clinical group

\begin{tabular}{ll}
\hline \multicolumn{1}{c}{ Inclusion criteria } & \multicolumn{1}{c}{ Exclusion criteria } \\
\hline $\begin{array}{l}\text { 1. Written diagnosis of SLI made by a speech } \\
\text { therapist }\end{array}$ & $\begin{array}{l}\text { 1. Past neurological infections, CNS traumas } \\
\text { or a history of epilepsy }\end{array}$ \\
$\begin{array}{l}\text { 2. Severe understanding speech disorder at } \\
\text { the age of } 2\end{array}$ & $\begin{array}{l}\text { 2. Incorrect results of additional } \\
\text { examinations:of hearing, of the brain } \\
\text { (MRI, EEG) }\end{array}$ \\
$\begin{array}{ll}\text { 3. Severe expressive language disorder at } \\
\text { the age of } 3\end{array}$ & $\begin{array}{l}\text { 3. Co-occurrence of a pervasive } \\
\text { developmental disorder, ADHD or } \\
\text { intellectual disability }\end{array}$ \\
$\begin{array}{l}\text { 4. Typical nonverbal development } \\
\begin{array}{l}\text { 5. Correct results of additional examinations: } \\
\text { of hearing, of the brain (MRI, EEG) }\end{array}\end{array}$ & $\begin{array}{l}\text { 5. Any pharmacotherapy during the past } \\
\text { six months (e.g., Hydroxisinum) }\end{array}$ \\
6. Typical motor development &
\end{tabular}

Because the ages of the children with SLI were not controlled during the recruitment process, this group was not homogeneous in age. To conduct a reliable comparison of the obtained results, we applied a matched pairs experimental design in which each child with an SLI was paired with a maximally similar healthy child (Hansen \& Klopfer, 2006). The matching criteria were as follows: 1$)$ age $\left(M_{\text {control }}=7.9, S D=2.04, C I_{95 \%}[3.4,11.9]\right.$, $\left.\left.M_{\text {clinical }}=8.1, S D=2.0, C I_{95 \%}[3.6,11.7]\right), 2\right)$ gender $(N=106,34$ boys and 19 girls in both groups), 3) parental educational level, and 4) stage of formal education realised by the child in kindergarten or at school. Using this procedure, two target groups were created. The clinical group (the SLI group - SLIG) comprised 53 children with SLI and the control group comprised 53 children with typical development (TD) .

By analysing the observed differences, we can state that the matched pairs procedure was successful in levelling the differences in all selected criteria. No differences were observed between the groups in age, which was precisely calculated to the day $(t(104)=0.11, p=.910)$. No significant differences were observed in the parental educational level (mothers: $W=$ $1421, p=.963$; fathers: $W=1423.5, p=.901)$ and the distribution of the stages of formal education $\left(\operatorname{chi}^{2}(8)=3.0, p=.934\right)$. Additionally, the level of fluid intelligence in both groups of subjects was compared using Raven's Coloured Progressive Matrices (RCPM; see Jaworowska \& Szustrowa, 2011). The raw RCPM scores also indicated no differences between the groups (range: 8-35, $M=23.9, S D=6.87, t(97)=1.80, p=.075)$.

\section{Materials}

The primary criterion for selecting the research tools used in the present study was their appropriateness for examining children as young as three years of age. 
The Children Card Sort (CCS) was applied to measure inhibitory control and cognitive flexibility. The CCS is a standardised method constructed based on the Dimensional Change Card Sort developed by Phillip Zelazo (2006). This tool considers the Polish language context and is characterised by a high reliability $\left(r_{\mathrm{tt}}=.85\right)$ and validity (correlation with age $r=.68$, for further information see: Jabłoński, Kaczmarek, \& Kleka, in press).

The procedure involves a sorting paradigm in which the children are required to sort a series of bivalent test cards. In the CCS, each card has two unequivocal traits allowing the card to be classified according to either of two dimensions: colour (blue or red) or shape (a house or a cat). The child is shown two target cards (e.g., a red house and a blue cat) and asked to sort a series of bivalent test cards (e.g., a red cat or a blue house) according to one dimension (e.g., colour). The children first sort the cards according to one dimension (colour) and then according to the other dimension (shape). Assignment is performed according to sorting rules previously explained by the researcher. To trigger inhibition control, the test procedure is divided into three phases (Zelazo, Frye, \& Rapus, 1996).

First, the participant is presented with the test cards, and the sorting rule is explained. After the presentation, the first and second phases begin with the proper sorting. The first phase of sorting, which is called the pre-switch phase, involves training the participant to sort the cards according to the previously introduced rule (sorting according to the colour). During the second phase of sorting, which is called the post-switch phase, the researcher changes the sorting rule (sorting according to the shape). In both cases, the child is reminded of the current sorting rule before the cards are displayed. This phase of the test concerns the ability to inhibit automatic reactions (prepotent reaction). The original version of the task, which is similar to the Polish CCS, was designed for older children and includes an additional third phase called the border version. The cards used in this version present the same pictures, but certain cards have black borders on the edges. In the border version, the sorting rules remain unchanged (sorting according to the colour or shape), but the researcher does not remind the participant of the sorting rule. The child decides how to sort the cards using the border as a clue. A card with a border requires sorting according to colour, whereas a card without a border requires sorting according to shape. During this phase, children have to remember this rule and respond accordingly using their memory of the stimulus. A detailed description of the procedure is presented in Table 2.

Inhibitory control is measured during the post-switch phase as the number of correct responses. During this phase, the child must inhibit the tendency to continue sorting the cards according to the rule established during the pre-switch phase and switch to the new standard. Cognitive 
flexibility is measured during the border phase, in which the child must change the criterion for sorting depending on whether he/she sees the black border.

The results of the CCS can be presented in two ways. First, the results of the test can be presented as the number of correct responses during each sorting phase of the procedure, separately or combined. Second, the results can be presented as the successful completion of a particular phase. To pass the post-switch phase, the child must sort at least 6 of 7 cards correctly. To pass the border phase, at least 9 of 12 cards must be sorted correctly. The thresholds for passing each of the two phases were calculated based on a binominal distribution in which the probability of choosing the correct answers by chance is less than 0.05 .

Table 2. Design of the Polish version of the Children Card Sort developed by Jabłoński, 2013

\begin{tabular}{ccc}
\hline Phase & Number of rounds & Sorting Task \\
\hline Trial phase & 2 Demonstration rounds & sorting by colour \\
I: Pre-switch phase & 7 Test rounds & sorting by colour \\
II: Post-switch phase & 7 Test rounds & sorting by shape \\
III: Border phase & 2 Demonstration rounds & cards with border are sorted \\
& $\begin{array}{c}\text { 12 Test rounds (including } \\
\text { six cards with border) }\end{array}$ & $\begin{array}{c}\text { colour, } \\
\end{array}$ \\
& & by shape \\
\hline
\end{tabular}

The Literacy Assessment Battery (LAB) was applied to measure literacy skills (for more details, see Jabłoński, 2013). This tool was constructed according to the cultural-historical model of reading and writing development (Jabłoński, 2002). This model assumes that to acquire the ability to use script, a new higher mental function, written speech, must be developed. The developmental changes characteristic of this acquisition are manifested as a changed understanding of the role of script in the process of communication. A significant advantage of this method is that LAB is appropriate for three years old children, who have not yet begun their formal education in reading and writing. The LAB consists of 9 tasks ordered from letters A to I, increasing in difficulty. The tasks are adequately diversified according to the stages of written speech development (see Table 3). The LAB has a high reliability and validity (Jabłoński, Kleka, 2015). Task A consists of two questions, and the subject is asked to answer the question or follow a single instruction. The questions are as follows: 1) What is that? (test administrator points to an illustrated written story) and 2) Why do people read? The instruction is as follows: Please show me what reading looks like. Performance on task $\mathrm{A}$ is an indicator of picture-print discrimination. Task B consists of three questions, and the subject is asked to answer the question or follow a single instruction. The questions are as follows: 1) What am I doing? (test 
administrator draws a simple picture), 2) What am I doing? (test administrator writes a simple sentence) and 3) Why do people write? The instruction is as follows: Please show me what writing looks like. Performance on task $\mathrm{B}$ is an indicator of drawing-writing discrimination. During task C, five charts are presented to the child. Each chart contains six labelled pictures of different objects. One of the pictures is a model. Another picture is identical to the model. The other four pictures of objects and labels are unpaired. Task C measures the visual recognition of labels and objects presented in pictures. During task D, four sets of five cards and one set of six cards are presented to the tested child. The child is asked to assess whether each card is identical to the model card. This task is designed to assess discrimination of words. Task E measures the ability to write the names of objects and copy words. During task E, a single chart with labelled pictures of six different objects is presented to the child. The objects and labels on this chart are unpaired. The subject is asked to write the names of three objects displayed on the chart that are spoken by the test administrator. During task F, a set of six cards with a single word on each card is presented to the child. The test administrator asks the subject the question "What is written on the card?" and waits until the child states whether he/she knows the answer. Then, the child provides the answer. Task F measures the reading of words and the performance of reading. The ability to write sentences and the method of writing are measured by task G. During this task, the child is asked to write the three sentences spoken by the test administrator one at a time. Task $\mathrm{H}$ is designed to measure two variables: reading comprehension and reading rate. During this task, the subject is presented with a chart displaying a short story. All sentences in the story lack a period and a capital letter marking the beginning and end of the sentence. The child must mark the end of each sentence by placing a period. The timing of this task is recorded. During task I, which is the final task in the battery, a single chart with a picture story is presented. The test administrator asks the child to write a short story based on the picture story. Task I is designed to measure the following three variables: grammar, syntax and the coherence of the story written by the child. The final results of the LAB are calculated separately for each of the 15 variables.

\section{Data analyses}

After matching the participants, Welch's t-test and Pearson's chi-square test were used to perform bivariate analyses of the inter-group differences. To analyse the performance of the two group in the CCS test, the mean number of correct responses was compared by the Welch t-test and followed by post hoc comparisons using the Bonferroni-Holm method to adjust the p-values.

Moreover, we used the Wilcoxon signed rank test to compare the means of correct answers and the Pearson chi-squared test to compare the percentages of children passing phase II and III of the CCS. To determine the importance 
of the results we used Cohen's d effect size coefficient, and we considered the results for $\mathrm{p}<0.05$ to be statistically significant. The analyses were conducted using R-project version 3.2.1 (R Core Team, 2017).

Table 3. Design of the Literacy Assessment Battery

\begin{tabular}{|c|c|c|c|}
\hline \multicolumn{3}{|c|}{ Variables } & \multirow{2}{*}{$\begin{array}{c}\text { Task } \\
\text { number }\end{array}$} \\
\hline Number & Name & Indicator & \\
\hline 1 & Picture-print discrimination & General performance on Task A & A \\
\hline 2 & $\begin{array}{l}\text { Drawing-writing discrimination } \\
\text { visual recognition }\end{array}$ & General performance on Task B & B \\
\hline 3 & $\begin{array}{l}\text { Names of objects presented } \\
\text { on pictures }\end{array}$ & The correctness of word selection & $\mathrm{C}$ \\
\hline 4 & Discrimination of words & $\begin{array}{l}\text { The correctness of word } \\
\text { discrimination }\end{array}$ & $\mathrm{D}$ \\
\hline 5 & Writing names of objects & $\begin{array}{l}\text { The correctness of object name } \\
\text { selection }\end{array}$ & $\mathrm{E}$ \\
\hline 6 & Copying of words & $\begin{array}{l}\text { The correctness of letter shape } \\
\text { and order }\end{array}$ & $\mathrm{E}$ \\
\hline 7 & Reading of words & $\begin{array}{l}\text { The correctness of word } \\
\text { recognition }\end{array}$ & $\mathrm{F}$ \\
\hline 8 & The way of reading & $\begin{array}{l}\text { Type of preparation to answer } \\
\text { (loud reading, whispering or } \\
\text { silent reading) }\end{array}$ & $\mathrm{F}$ \\
\hline 9 & Writing of sentences & $\begin{array}{l}\text { The correctness of sentence } \\
\text { writing }\end{array}$ & G \\
\hline 10 & The way of writing & $\begin{array}{l}\text { Type of behaviour during writing } \\
\text { (loud reading, whispering or silent } \\
\text { reading) }\end{array}$ & G \\
\hline 11 & Reading comprehension & $\begin{array}{l}\text { The correctness of marking } \\
\text { the ends of sentences }\end{array}$ & $\mathrm{H}$ \\
\hline 12 & Reading rate & Duration of task performance & $\mathrm{H}$ \\
\hline 13 & Grammar & Grammar correctness of sentences & I \\
\hline 14 & Syntax & Syntax correctness of sentences & I \\
\hline 15 & Coherence & $\begin{array}{l}\text { The correctness of phrases } \\
\text { increasing text coherence }\end{array}$ & I \\
\hline
\end{tabular}

\section{Results}

\section{Inhibitory control and cognitive flexibility}

To determine whether typically developing children outperform SLI children in EFs, we compared the results of phases II and III of the CCS between the groups. The level of inhibitory control in the investigated groups, as measured using the mean number of correct answers in phase II of the CCS, 
did not differ based on the result of the t-test $(t(102)=.190, p=.850$, $\left.d=-.02, C I_{95 \%}[-.55, .22]\right)$. The mean of the SLIG was $6.49(S D=0.57)$, and the mean of the TD group was $6.56(S D=0.14)$. The percentage of children who passed the second stage of the CCS was also comparable between the groups. In total, $95 \%$ of the boys and $88 \%$ of the girls in the clinical group completed this stage, whereas $94 \%$ of the boys and $89 \%$ of the girls in the control group completed this stage.

The level of cognitive flexibility (as measured using the mean number of correct answers in third phase of the CSS) was higher in the group of typically developing children $(M=9.13, S D=2.20)$ than in the group of children with SLI $(M=7.53, S D=1.98)$ based on the result of the t-test $\left(t(103)=3.95 ; p<.001, d=.76, C 19_{5 \%}[0.37,1.16]\right)$. Moreover, a difference was observed between the two groups in the frequency of passing phase III of the $\operatorname{CCS}\left(\operatorname{chi}^{2}(1)=7.57 ; p=.006, d=.56, C I_{95 \%}[.15, .95]\right)$. The cards with the black border were sorted correctly by $29 \%$ of the boys and $26 \%$ of the girls in the SLIG and by $56 \%$ of the males and $58 \%$ of the girls in the TD group (Table 4).

Table 4. Results of the CCS according to gender, age, and group

Clinical group (SLIG)

Passers/all subjects

$M(S D)$

\begin{tabular}{|c|c|c|c|c|c|c|c|c|}
\hline Phase & 2nd & 3rd & $\begin{array}{l}\text { all correct } \\
\text { items }\end{array}$ & $\begin{array}{l}\text { passed } \\
\text { phases }\end{array}$ & 2nd & 3rd & $\begin{array}{l}\text { all correct } \\
\text { items }\end{array}$ & $\begin{array}{l}\text { passed } \\
\text { phases }\end{array}$ \\
\hline \multicolumn{9}{|c|}{ Gender } \\
\hline Boys & $32 / 34$ & $10 / 34$ & $20.9(3.13)$ & $2.2(0.59)$ & $30 / 34$ & $19 / 34$ & $22.3(3.23)$ & $2.4(0.66)$ \\
\hline Girls & $17 / 19$ & $5 / 19$ & $20.7(2.73)$ & $2.1(0.62)$ & $18 / 19$ & $11 / 19$ & $23.3(2.38)$ & $2.5(0.61)$ \\
\hline \multicolumn{9}{|c|}{ Years of age } \\
\hline 3 & $4 / 4$ & $0 / 4$ & $20(1.83)$ & $1.8(0.5)$ & $1 / 3$ & $0 / 3$ & $18.7(3.06)$ & $1.3(0.58)$ \\
\hline 4 & $1 / 2$ & $0 / 2$ & $16(5.66)$ & $1.5(0.71)$ & $1 / 2$ & $0 / 2$ & $17(5.66)$ & $1.5(0.71)$ \\
\hline 5 & $6 / 6$ & $2 / 5$ & $20(2.1)$ & $2(0.63)$ & $7 / 7$ & $2 / 7$ & $21.7(1.38)$ & $2.3(0.49)$ \\
\hline 6 & $7 / 7$ & $2 / 7$ & $22.1(1.68)$ & $2.3(0.49)$ & $7 / 8$ & $1 / 8$ & $20.1(2.7)$ & $2(0.53)$ \\
\hline 7 & $7 / 7$ & $2 / 7$ & $21.4(1.9)$ & $2.3(0.49)$ & $7 / 7$ & $4 / 7$ & $23(2)$ & $2.6(0.53)$ \\
\hline 8 & $11 / 11$ & $5 / 11$ & $22.8(2.4)$ & $2.5(0.52)$ & $10 / 11$ & $10 / 11$ & $24.5(1.63)$ & $2.8(0.4)$ \\
\hline 9 & $4 / 6$ & $1 / 6$ & $18.2(4.54)$ & $1.8(0.75)$ & $4 / 4$ & $4 / 4$ & $25.5(1)$ & $3(0)$ \\
\hline 10 & $8 / 8$ & $1 / 8$ & $20.9(2.17)$ & $2(0.53)$ & $7 / 7$ & $6 / 7$ & $24.4(1.51)$ & $2.9(0.38)$ \\
\hline 11 & $2 / 2$ & $1 / 2$ & $21(2.83)$ & $2.5(0.71)$ & $4 / 4$ & $3 / 4$ & $23.8(1.89)$ & $2.8(0.5)$ \\
\hline
\end{tabular}

Typically developing children (TD)

Passers/all

$M(S D)$ 


\section{Level of literacy}

The second hypothesis tested in this study was that typically developing children outperform SLI children in literacy measures. To verify this hypothesis, we conducted an analysis of the literacy level in the two investigated groups. As shown in Table 5, the number of children included in the comparisons differed depending on the variable due to the lack of data because of the diversified difficulty of particular components of the LAB. Average results between groups were compared using the Wilcoxon signed rank test with correction for p-values for multiple comparisons. The SLIG and the TD group differed in the LAB results only in the reading rate (the speed of sentence separation). The children in the clinical group executed this task more slowly than the healthy children $\operatorname{did}\left(V=593.5, p=.030, d=.60, C I_{95 \%}[.20, .99]\right)$. The hypothesis that the investigated groups have a different level of literacy was supported in 1 of the 15 variables measured by the LAB.

Table 5. Descriptive statistics of the LAB scores in the clinical (SLIG) group and typically developing children (TD)

\begin{tabular}{clccccccc}
\hline \multirow{2}{*}{ No. } & \multicolumn{1}{c}{$\begin{array}{c}\text { Variables } \\
\text { name }\end{array}$} & \multicolumn{3}{c}{ SLIG } & \multicolumn{5}{c}{ TD } & & adj. \\
\hline 1 & Picture-print discrimination & 53 & 71.4 & 28.8 & 53 & 80.5 & 23.3 & .696 \\
2 & Drawing-writing discrimination & 53 & 74.3 & 23.6 & 53 & 82.1 & 18.1 & .410 \\
3 & Visual recognising names of & 53 & 78.5 & 26.5 & 53 & 85.7 & 22.1 & 1 \\
& objects presented on pictures & & & & & & & \\
4 & Discrimination of words & 53 & 87.5 & 27.3 & 53 & 92.5 & 19.6 & 1 \\
5 & Object names writing & 53 & 69.2 & 41.1 & 53 & 83.6 & 32.6 & .459 \\
6 & Copying of words & 53 & 73.8 & 41.4 & 53 & 87.0 & 29.9 & 1 \\
7 & Reading of words & 53 & 60.7 & 48.4 & 53 & 73.3 & 40.6 & 1 \\
8 & The way of reading & 53 & 52.1 & 44.4 & 53 & 66.6 & 40.6 & .784 \\
9 & Writing of sentences & 53 & 46.2 & 44.8 & 53 & 65.0 & 43.1 & .140 \\
10 & The way of writing & 53 & 42.6 & 42.7 & 53 & 65.8 & 38.9 & .247 \\
11 & Reading comprehension & 28 & 40.8 & 36.6 & 34 & 63.0 & 37.9 & .324 \\
12 & Reading rate* & 53 & 23.9 & 36.5 & 53 & 47.6 & 42.7 & .030 \\
13 & Grammar & 16 & 83.4 & 21.9 & 35 & 89.7 & 21.7 & 1 \\
14 & Syntax & 16 & 67.4 & 28.1 & 34 & 69.1 & 30.9 & 1 \\
15 & Coherence & 16 & 30.7 & 14.5 & 35 & 22.3 & 20.2 & .324 \\
\hline
\end{tabular}

\section{Discussion}

The main aim of the current study was to compare executive functions and literacy between two groups of children (typically developing and children suffering from SLI), aged 3 to 11 years. We found no differences between 
the compared groups in the level of inhibitory control. However, the children with SLI presented a lower level of cognitive flexibility than the control group.

The results obtained by our team appear to be consistent with the findings reported by Marton (2008) and Farrant et al. (2012). In these studies, which were both based on the sorting card paradigm, the performance of children with SLI was significantly poorer in the cognitive flex-ibility task. Bishop and Norbury (2005) proposed the hypothesis that children with neurodevelopmental disorders, including SLI, show clinically significant levels of inattention, which is considered one of the leading causes of failure in this task. Similar to Farrant et al. (2012), we agree that to explain the obtained results it is worth referring to the underlying theory of the sorting card test (ibid.). The Cognitive Complexity and Control Theory is a current theory considered applicable to unsuccessful performance in this task (Frye, Zelazo, \& Burack, 1998). According to this theory, the differences in executing the sorting task are associated with the level of a child's ability to use complex rules in solving tasks. "Complexity" is defined using a hierarchical structure of rules in which rules are events with an "if - then" type of structure, and the level of complexity reflects the number of degrees of rules embedded in the hierarchical structure. This theory differentiates rules with a simple "if - then" structure from those with a complex, hierarchical structure of "if - if - then". To execute the border version of the CCS test, it is necessary to activate the complex hierarchical structure ("if - if - then"), whereas in the previous stages (i.e., the pre- and post-switch phase) only the "if - then" rule is activated. It may be difficult for children with language problems to represent complex rules in grammatical structures and then to apply these rules in a given situation. Therefore, the level of rule complexity can potentially explain the appearance of errors in the group of children with SLI.

Difficulties in a task that examines cognitive flexibility can also hypothetically result from a lowered ability to store and manipulate the material in working memory. Working memory is required in the task of sorting cards with borders because the subject is not reminded of the sorting rule (i.e., the person must remember the rule independently). This assumption is based on Baddeley and Hitch's theory (Baddeley \& Hitch, 1974). In their experimental study, the authors distinguished the following three components of working memory: two memory stor-age units (phonological and spatialvisual) and a system that manages attention resources and the functioning of these storage units, the so-called central executive system. According to the authors, a significant factor that increases the capacity of working memory between the ages of 7 and 8 years is the process of subvocalisation (inner speech), which cannot be observed in younger children (Gathercole, Adams, \& Hitch 1994). The word-length effect provides the most convincing evidence confirming the existence of subvocal articulation. In the word-length effect, longer words are more difficult to memorise because their repetition 
in the pho-nological loop requires more time than the articulation of shorter words in memory. Compared to older children who speak faster, the lower pace of articulation in younger children can lead to greater problems in recalling the memorised material. Difficulties in remembering simple spoken sentences, which engage the phonological loop, in patients with SLI have been documented in the literature. A study conducted by Jonson indicated that the assessment of language fitness provides an accurate prediction of EF fitness (Jonson, as cited in Jodzio 2008, p. 118).

We cannot eliminate the possibility that the lack of differences in inhibitory control and the occurrence of differences in cognitive flexibility resulted from the distribution of ages in the investigated groups. The dynamic development of inhibitory control can be observed between the ages of 3 and 5. However, these ages were rather poorly represented in the sample ( 24 children in 3 age groups: 3-, 4- and 5-year-olds). An increase in cognitive flexibility within the scope measured by the CCS occurs at approximately the age of 7, and this age is better represented in the sample (67 children in 5 age groups: 7-, 8-, 9-, 10- and 11-year-olds) (Zelazo et al. 2003).The obtained results did not fully confirm our second hypothesis that SLI children have lower levels of literacy skills than typically developing children. The children in the clinical group differed from the healthy children in only one of fifteen indicators of literacy development (i.e., reading rate). Notably, the investigated children with SLI might have un-dergone a prior therapeutic intervention that included enhancing written communication. Thus, a likely explanation of the lack of differences could be the successful compensation for the ability to read and write in the SLIG. Unfortunately, both the duration and scope of this intervention were not controlled in this study.

Another explanation for the lack of differences in the level of reading and writing skills between the clinical and control groups may be the scope of the measurements of these competencies in the present study. The lower level of ability to read and write in children with SLI manifests in more complex tasks that require conducting an analysis or creating texts. Such requirements can be found in task IX (variable no. 13, 14 and 15) of the LAB, in which the child must write a story to describe a set of pictures. Interestingly, we could include a maximum of $35(66 \%)$ children from the control group and only $16(32 \%)$ children from the clinical group in the statistical analysis of this task due to the lack of data in the remaining cases. The difference in the number of children who were able to complete task IX could indicate that this task was more complicated for the children with SLI than for the healthy children.

An additional aim of our study was to determine the practicality of the tools. We sought to determine whether the new cognitive assessment tools could be used to screen children for SLI. The Children Card Sort test designed to assess EFs was an efficient tool for differentiating the level of cognitive flexibility development between the children suffering from an SLI and 
the control group examined in our study. However, the use of the CCS for testing the level of inhibitory control in SLI children remains unclear. Because our sample underrepresented the 3-, 4- and 5-year-old age groups, we were unable to verify the use of this tool to measure the dynamic development of inhibitory control. Furthermore, the Literacy Assessment Battery was likely too simple for the children in both groups, and the use of all the tasks in a screening procedure for an SLI diagnosis would be pointless. Future studies should consider a verification of task IX of the LAB as a screening test for SLI, separately from the entire LAB.

Longitudinal or experimental studies are required to reliably verify the hypotheses related to cause-and-effect dependencies among SLI, executive functions, and academic skills. In such studies, it would be necessary to carefully control the sampling of the clinical group in terms of the size of the sample with a delay in speech development and the timing of the initiation of SLI therapy. In addition, more balanced samples across age groups are necessary.

\section{Conclusion}

SLI constitute a heterogeneous group of disorders characterised by a serious delay in the development of the ability to use the "mother tongue", but the cause of SLI remains unknown. Various studies (Bishop \& Norbury, 2005, Farrant et al., 2012, Kapa \& Plante, 2015, Vissers et al., 2015) support the hypothesis that language acquisition plays a role in executive function development. Both disorders in speech development and irregularities in the development of executive functions are considered significant risk factors for difficulties in school achievement (Molfese et al., 2010, Jacobson, Williford \& Pianta, 2011, Clark et al., 2013, Blair \& Razza 2007). Therefore, identifying children in the SLI risk group (so-called late talkers) by screening for executive function abilities appears entirely justifiable, and the Chil-dren Card Sort test appears to be a suitable tool for such screening. Additionally, a further ex-ploration of the mutual relationships between speech and executive functions in this group of children and adolescents appears necessary.

\section{Acknowledgements}

Funding source: Polish Ministry of Science and Higher Education, under grant no. NN106 047839 en-titled: Construction of tools for psychological assessment of learning readiness of children between the age of 3 and 11. 


\section{References}

Baddeley, A. D., \& Hitch, G. (1974). Working memory. In G.H. Bower (Ed.), The psychology of learning and motivation: Advances in research and theory. 8, 47-89. New York, NY: Academic Press. doi:10.1016/S00797421(08)60452-1

Barkley, R. A. (1997). Inhibition, sustained attention, and executive functions: Constructing a unified theory of ADHD. Psychology Bulletin, 121, 5-94. doi:10.1037/0033-2909.121.1.65

Beswick, J. F., \& Sloat, E. A. (2006). Early literacy success: A matter of social justice. Education Canada, 46(2), 23-26.

Bishop, D. V. (2006). What Causes Specific Language Impairment in Children? Current Directions in Psychological Science, 15(5), 217-221. doi:10.1111/ j.1467-8721.2006.00439.x

Bishop D.V. \& Norbury, C.F. (2005). Executive functions in children with communication impairments, in relation to autistic symptomatology. 2: Response inhibition. Autism, 9 (1), 29-43. doi:10.1177/136236130504 9028

Blair, C. \& Razza, R. P. (2007). Relating effortful control, executive function, and false belief understanding to emerging math and literacy ability in kindergarten. Child Development, 78(2), 647-663. doi:10.1111/j.14678624.2007.01019.x

Botting, N., Jones, A., Marshall, C., Denmark, T., Atkinson, J., \& Morgan, G. (2017), Nonverbal Executive Function is Mediated by Language: A Study of Deaf and Hearing Children. Child Development, 88. 1689-1700. doi:10.1111/cdev.12659

Chan, R. C., Shum, D., Toulopoulou, T., \& Chen, E. Y. (2008). Assessment of executive functions: Review of instruments and identification of critical issues. Archives of Clinical Neuropsychology, 23(2), 201-216. doi:10.10 16/j.acn.2007.08.010

Clark, C. A., Sheffield T. D., Wiebe, S. A., \& Espy, K. A. (2013). Longitudinal associations between executive control and developing mathematical competence in preschool boys and girls. Child Development, 84(2), 662-677. doi:10.1111/j.1467-8624.2012.01854.x

Conti-Ramsden, G., Bishop, D. V. M., Clark, B., Norbury, C. F., \& Snowling, M. J. (2014). Specific language impairment (SLI): The internet RALLI campaign to raise awareness of SLI. Psychology of Language and Communication, 18(2), 143-148. doi: 10.2478/plc-2014-0011

Conti-Ramsden, G., Mok, P. L., Pickles, A., \& Durkin, K. (2013). Adolescents with a history of specific language impairment (SLI): Strengths and difficulties in social, emotional and behavioral functioning. Research In Developmental Disabilities, 34(11), 4161-4169. doi:10.1016/j.ridd. 2013.08.043 
Cuevas, K., Deater-Deckard, K., Kim-Spoon, J., Watson A. J., Morasch., K. C., \& Bell, M. A. (2014). What's mom got to do with it? Contributions of maternal executive function and caregiving to the development of executive function across early childhood. Developmental Science, 17(2), 224-238. doi:10.1111/desc.12073

Cumming, R., Wilson, A., \& Goswami, U. (2015). Basic auditory processing and sensitivity to prosodic structure in children with specific language impairments: A new look at a perceptual hypothesis. Frontiers in Psychology, 10(6), 972. doi:10.3389/fpsyg.2015.00972

Diamond, A. (2013). Executive Functions. Annual Review of Psychology, 64, 135-168. doi:10.1146/annurev-psych-113011-143750

Doebel, S., \& Zelazo, P. D. (2016). Seeing conflict and engaging control: Experience with contrastive language benefits executive function in preschoolers. Cognition, 157, 2019-226. doi:10.1016/j.cognition.2016. 09.010

Espy, K. A., Kaufmann, P. M., Glisky, M. L., \& McDiarmid, M. D. (2001). New procedures to assess executive functions in preschool children. Clinical Neuropsychologist, 15(1), 46-58. doi: 10.1076/clin.15.1.46.1908

Farrant, B.M., Maybery, M.T., \& Fletcher, J. (2012). Language, Cognitive Flexibility, and Explicit False Belief Understanding: Longitudinal Analysis in Typical Development and Specific Language Impairment. Child Development, 83(1), 223-235. doi:10.1111/j.1467-8624.2011. 01681.x

Flapper, B.C., \& Schoemaker, M.M. (2013). Developmental coordination disorder in children with specific language impairment: Comorbidity and impact on quality of life. Research in Developmental Disabilities, 34(2), 756-63. doi:10.1016/j.ridd.2012.10.014

Frye, D., Zelazo, P. D., \& Burack, J. A. (1998). I. Cognitive complexity and control: Implications for theory of mind in typical and atypical development. Current Directions in Psychological Science, 7, 116-121.

Gathercole, S. E., Adams, A. M., \& Hitch, G. J. (1994). Do young children rehearse? An individual differences analysis. Memory \& Cognition, 22(2), 201-207.

Hansen, B. B., \& Klopfer, S.O. (2006). Optimal full matching and related designs via network flows. Journal of Computational and Graphical Statistics, 15, 609-627. doi:10.1198/106186006X137047

Henry, L. A., Messer, D. J., \& Nash, G. (2012). Executive functioning in children with specific language impairment. Journal of Child Psychology and Psychiatry, 53(1), 37-45. doi:10.1111/j.1469-7610.2011.02430.x

Horowitz-Kraus, T., \& Finucane, S. (2016). Separating the different domains of reading intervention programs: A review. SAGE Open, 6(2), 1-26. 
Im-Bolter, N., Johnson, J., \& Pascual-Leone, J. (2006). Processing limitations in children with specific language impairment: The role of executive function. Child Development, 77, 1822-1841. doi:10.1111/j.1467-8624. 2006.00976.x

Isoaho, P., Kauppila, T. and Launonen, K. (2015). Specific language impairment (SLI) and reading development in early school years. Child Language Teaching and Therapy, 32(2), 147-157.

Jabłoński, S. (2002). Written speech development: A cultural-historical approach to the process of reading and writing ability acquisition. Psychology of Language and Communication, 6(2), 53-64.

Jabłoński, S. (2013). Inhibitory control and literacy development among 3to 5-year-old children. L1-Educational Studies in Language and Literature, 13, 1-25.

Jabłoński, S. (2015). Assessment of literacy development from cultural-historical perspective. International Journal of Arts and Sciences, 8(1), 133-146.

Jabłoński, S., Kaczmarek, I., Kaliszewska-Czeremska, K., \& Zakrzewska, M. (2013). Sortowanie kart jako metoda badania giętkości poznawczej u dzieci w wieku 3-8 lat [Card sorting as a method for cognitive flexibility assessment in 3 to 8 years old children]. Edukacja, 1(121), 54-72.

Jabłoński, S., Kaczmarek, I., \& Kleka, P. (in press). Test Sortowania Kart dla Dzieci - podręcznik [Children Card Sort - manual]. Gdańsk: Pracownia Testów Psychologicznych i Pedagogicznych.

Jabłoński, S., \& Kleka, P. (2015). Pomiar rozwoju mowy pisanej jako nowa propozycja oceny poziomu umiejętności posługiwania się pismem u dzieci w wieku 3-11 lat [Assessment of written speech development as a new proposal of literacy assessment in children aged 3-11 years]. Polskie Forum Psychologiczne, 20(3), 380-408.

Jacobson, L. A., Williford, A. P., \& Pianta, R. C. (2011). The role of executive function in children's competent adjustment to middle school. Child Neuropsychology, 17(3), 255-280. doi:10.1080/09297049.2010.53 5654

Jaworowska, A. \& Szustrowa, T. (2011). Test matryc Ravena w wersji kolorowej. Formy: Klasyczna i równoległa. Podręcznik. Warszawa: Pracownia Testów Psychologicznych Polskiego Towarzystwa Psychologicznego.

Jodzio, K. (2008). Neuropsychologia intencjonalnego działania. Koncepcje funkcji wykonawczych. Warszawa: Wydawnictwo Naukowe Scholar.

Kapa, L. L., \& Plante, E. (2015). Executive function in SLI: Recent advances and future directions. Current Developmental Disorders Reports, 2(3), 245-252. doi:10.1007/s40474-015-0050-x

Kwieciński, Z. (2002). Nieuniknione?: Funkcje alfabetyzacji $w$ dorostości [Unavoidable?: The role of alphabetization in adulthood]. Torun: Wydawnictwo Uniwersytetu Mikołaja Kopernika; Olsztyn: Uniwersytet Warmińsko-Mazurski. 
Leonard L. B. (2014). Children with Specific Language Impairment. Cambridge, MA: MIT Press.

Leonard, L. B., Deevy, P., Fey, M. E., \& Bredin-Oje, S. L. (2013). Sentence comprehension in specific language impairment: A task designed to distinguish between cognitive capacity and syntactic complexity. Journal of Speech, Language, and Hearing Research, 56, 577-589. doi:10.1044/ 1092-4388(2012/11-0254)

Li, N., \& Bartlett, C. W. (2012). Defining the genetic architecture of human developmental language impairment. Life Sciences, 90(13-14), 469-475. doi:10.1016/j.lfs.2012.01.016

Lindstone, J. S., Meins, E., \& Fernyhough, C. (2012). Verbal mediation of cognition in children with specific language impairment. Developmental Psychopathology, 24(2), 651-660. doi:10.1017/S0954579412000223

Lukács, Á., Ladányi, E., Fazekas, K., \& Kemény, F. (2016). Executive functions and the contribution of short-term memory span in children with specific language impairment. Neuropsychology, 30(3), 296-303. doi:10.1037/ neu0000232

Marton, K. (2008). Visuo-spatial processing and executive functions in children with specific language impairment. International Journal of Language \& Communication Disorders, 43(2), 181-200. doi:10.1080/16066350701340719

Marton, K., Campanelli, L., Scheuer, J., Yoon, J., \& Eichorn, N. (2012) Executive function profiles in children with and without specific language impairment. Journal of Applied Psycholinguistics, 12, 57-73.

Mayes A. K., Reilly S., Morgan A. T. (2015). Neural correlates of childhood language disorder: A systematic review. Developmental Medicine and Child Neurology, 57, 706-717. doi:10.1111/dmcn.12714

McLaughlin, M. R. (2011). Speech and language delay in children. American Family Physician, 83(10), 1183-1188.

Miller C., Kail R., Leonard L., \& Tomblin J. B. (2001). Speed of processing in children with specific language impairment. Journal of Speech, Language, and Hearing Research, 44, 416-433.

Miyake, A., Friedman, N.P., Emerson, M.J, Witzki, A. H, Howerter. A., \& Wager. T. D. (2000). The unity and diversity of executive functions and their contributions to complex "Frontal Lobe" tasks: A latent variable analysis. Cognitive Psychology, 41(1),49 -100. doi10.1006/cogp.1999. 0734

Molfese, V. J., Molfese, P. J. Molfese, D. L., Rudasill, K. M., Armstrong, N., \& Starkey, G. (2010). Executive function skills of 6 to 8 year olds: Brain and behavioral evidence and implications for school achievement. Contemporary Educational Psychology, 35(2), 116-125. doi:10.1016/j. cedpsych.2010.03.004 
Montgomery, J. W., Magimairaj, B. M., \& Finney, M. C. (2010). Working Memory and Specific Language Impairment: An Update on the Relation and Perspectives on Assessment and Treatment. American Journal of Speech-Language Pathology, 19(1), 78-94. doi:10.1044/1058-0360 (2009/09-0028)

O'Hare, A., \& Bremner, L. (2016). Management of developmental speech and language disorders: Part 1. Archives of Disease in Childhood, 101(3), 272-277. doi:10.1136/archdischild-2014-307394

Pauls, L. J., \& Archibald, L. M. (2016). Executive functions in children with specific language impairment: A meta-analysis. Journal of Speech, Language, and Hearing Research, 59(5), 1074-1086. doi:10.1044/2016_ JSLHR-L-15-0174

Petruccelli, N., Bavin, E. L., \& Bretherton, L. (2012). Children with specific language impairment and resolved late talkers: Working memory profiles at 5 years. Journal of Speech Language and Hearing Research, 55(6), 1690-1703. doi:10.1044/1092-4388(2012/11-0288)

$\mathrm{R}$ Core Team (2017). $R$ : A language and environment for statistical computing $R$ Foundation for Statistical Computing, Vienna, Austria. https://www.Rproject.org/.

Rice, M. L. (2013). Language growth and genetics of specific language impairment. International Journal of Speech-Language Pathology, 15(3), 223-233. doi:10.3109/17549507.2013.783113

Redmond, S. M., \& Rice, M. L. (1998). The socioemotional behaviors of children with SLI: Social Adaptation or Social Deviance? Journal of Speech Language and Hearing Research, 41(3), 688-700.

Shriberg, L. D., Tomblin, J. B., \& McSweeny, J. L. (1999). Prevalence of speech delay in 6-year-old children and comorbidity with language impairment. Journal of Speech Language and Hearing Research, 42(6), 1461-1481. doi:10.1044/jslhr.4206.1461

Spaulding T. J. (2010). Investigating mechanisms of suppression in preschool children with specific language impairment. Journal of Speech Language and Hearing Research, 53, 725-738. doi:10.1044/1092-4388(2009/ 09-0041)

Tarkowski, Z. (1992). Test Sprawności Językowej. Lublin: Wydawnictwo Polskiej Fundacji Zaburzeń Mowy.

Tomblin, J. B., Records, N. L., Buckwalter, P., Zhang, X., Smith, E., \& O'Brien, M. (1997). Prevalence of specific language impairment in kindergarten children. Journal of Speech Language and Hearing Research, 40(6), 1245-1260.

Vissers, C., Koolen, S., Hermans, D., Scheper, A., \& Knoors, H. (2015). Executive functioning in preschoolers with specific language impairment. Frontiers in Psychology, 6, 1574. doi:10.3389/fpsyg.2015.01574 
Weismer, S. E. (2013). Developmental Language Disorders: Challenges and mplications of Cross-Group Comparisons. Folia Phoniatrica et Logopaedica, 65 (2): 68-77. doi:10.1159/00035389

Williams, G. J., Larkin, R. F., Blaggan, S. (2013). Written language skills in children with specific language impairment. International Journal of Language and Communication Disorders, 48(2), 160-171. doi:10.1111/ 1460-6984.12010

World Health Organization. (1992). The ICD-10 classification of mental and behavioural dis-orders: Clinical descriptions and diagnostic guidelines. Geneva: WHO

Zelazo, P. D. (2006). The Dimensional Change Card Sort (DCCS): A method of assessing executive function in children. Nature Protocols, 1, 297-301. doi:10.1038/nprot.2006.46

Zelazo, P. D., Frye, D., \& Rapus, T. (1996). An age-related dissociation between knowing rules and using them. Cognitive Development, 11, 37-63. doi:10.1016/S0885-2014(96)90027-1

Zelazo, P. D., Mueller, U., Frye, D., \& Marcovitch S. (2003). The development of executive function in early childhood. Monographs of the Society for Research in Child Development, 68, 1-137. 